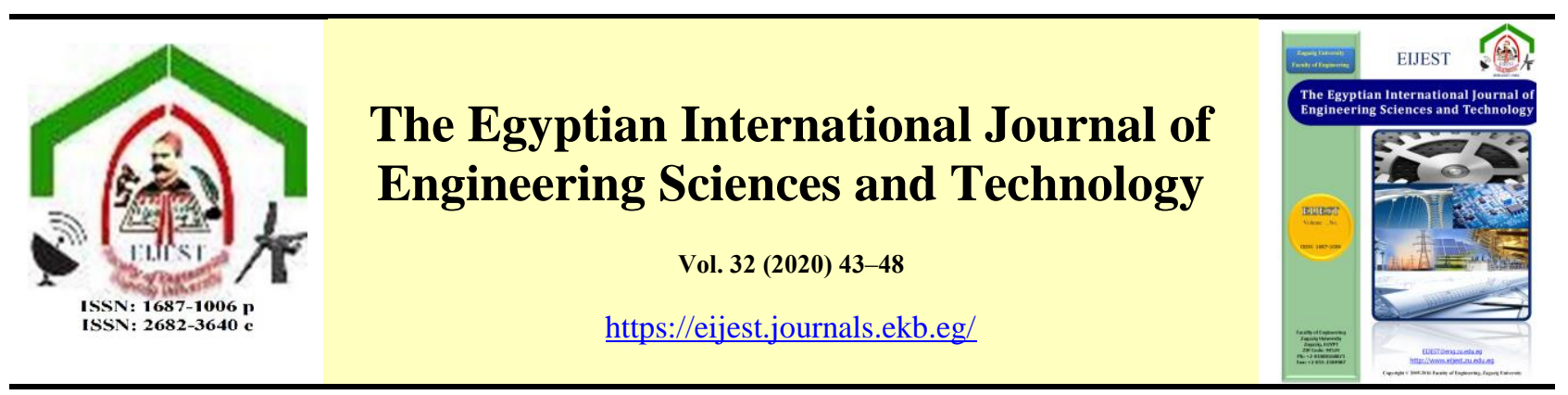

\title{
Evaluation of palm kernel shell and its nano-variant as aggregates in asphalt concrete
}

\author{
Opeyemi A. Gbadewole ${ }^{\text {a*}}$, Funmilayo M.Alayaki ${ }^{a}$, Adebola A.Adekunle ${ }^{\text {a }}$, Pius O.Dada ${ }^{\text {b }}$ \\ ${ }^{a}$ Department of Civil Engineering, Federal University of Agriculture, Abeokuta, 110001, Nigeria \\ ${ }^{b}$ Department of Agric \& Bio-resources Engineering, Federal University of Agriculture, Abeokuta, 110001, Nigeria
}

\begin{tabular}{|c|c|}
\hline A R T I CLE I N F O & A B S T RACT \\
\hline $\begin{array}{l}\text { Keywords: } \\
\text { Nano-technology } \\
\text { Palm-kernel-shell } \\
\text { Asphalt-concrete } \\
\text { Marshal-stability }\end{array}$ & $\begin{array}{l}\text { This study investigated the influence of palm kernel shell (PKS) and its calcined } \\
\text { nanomaterial (CN-PKS) as aggregates on the volumetric and Marshall Properties of } \\
\text { hot mix asphalt concrete. The PKS and CN-PKS were used to replace the coarse } \\
\text { aggregates and the filler material at 5, 10,15, } 20 \text { and } 25 \% \text { each in the same asphalt } \\
\text { mix in three replicates. The compositions were mixed together and compacted with } \\
50 \text { blows on both sides to obtain cylindrical samples for the Marshall Stability tests. } \\
\text { Volumetric parameters (density, air void, voids filled with bitumen, marshal } \\
\text { stability and flow) were carried out on asphalt cores to evaluate the strength of the } \\
\text { mixes. Mean values were presented for the tested parameters. All the percent of } \\
\text { PKS and CN-PKS mix proportions are within the limits of specification. The } \\
\text { optimum stability and percentage air void value was recorded at } 20 \% \text {. Utilizing } \\
\text { PKS and CN-PKS at } 5 \% \text { and } 15 \% \text { will most likely cause rutting and bleeding of the } \\
\text { flexible pavement due to low percent air void. This study concluded that partial } \\
\text { replacement with PKS and CN-PKS as coarse and filler at } 20 \% \text { in the same hot } \\
\text { mixed asphalt can improve the properties of asphalt concrete for use in medium } \\
\text { traffic roads }\end{array}$ \\
\hline
\end{tabular}

\section{Introduction}

Concrete has gained a lot of consideration as a widely used entity in construction material today. Generally, any concrete material is made up of at least $75 \%$ by volume of aggregate materials which may be abundant in some places. However in some settings, it may be economical to substitute those natural aggregates by more cheaply and readily available materials. Several studies over the years have researched into the subject of aggregate supplies and needs exploring the possibility of using waste materials as aggregates for concrete [1-4]. Attempts have been made therefore to replace natural aggregates in conventional asphalt and even cement concrete materials by locally available materials such as sintered domestic refuse [1], palm kernel shell [2], palletized blast furnace slag [3] and most widely recycled concrete [4-5].

On one hand, critical shortage of natural aggregate for production of asphalt concrete is now emerging in many regions [6] and this call for employment of alternatives to these aggregates. On the other hand, there is need for better methods of solid waste disposal [7]. In most third world countries where technological development is still growing, some regions especially large urban areas already have a problem in obtaining adequate aggregate

\footnotetext{
* Corresponding author. Tel.: +234-08140589220

E-mail address: opeyemigbadewole@gmail.com
} 
supplies at reasonable cost [8]. These aforementioned problems have contributed immensely to the increasing interest in using solid waste as alternatives to the conventional concrete aggregates.

Palm kernel shell (PKS) is currently being explored as partial replacement of coarse and fine aggregates in hot mix asphalt. It is very abundant in Nigeria, being a palm oil producing country. Several studies have reported the use of PKS in hot mixed asphalt indicating its good and promising potential as partial replacement for asphalt concrete aggregates [9-10].

Nanotechnology involves the use of very small particles of material either by themselves or through their manipulation to create new large scale materials. Nanotechnology is the re-engineering of materials and devices by controlling the matter at the atomic level [11]. In simple terms, it involves the creation of new and improved material form larger ones. In view of this, we believed that the full potential of PKS can be harnessed by introducing Nanotechnology and incorporating a combination of its nano and micro sizes as aggregates together in the same asphalt concrete mix. However, reports on nano-structuring of PKS and its effect on hot-mixed asphalt concrete are very few.

Therefore, this research is to investigate the influence of palm kernel shell (PKS) and its calcined nanomaterial (CN-PKS) as aggregates together in the same mix on the volumetric and Marshall Properties of hot mix asphalt concrete, with a view to fill some of the research gaps and provide more information in this area. Economically and environmentally, this will help to prevent indiscriminate disposal of unused PKS and also reduce the impact of blasting and excavation of rocks to make smaller particles for use in asphalt concrete.

\section{Materials and Methods}

The materials used for this research include conventional coarse and fine aggregates (granite and sharp sand respectively), filler material (stone dust), palm kernel shells and bitumen. The research involved a few stages including; the sourcing and preliminary tests of materials, production of the nanomaterial from palm kernel shell, determination of optimum bitumen content, evaluation of the effect of palm kernel shell and its nanomaterial on the volumetric and Marshall Properties of asphalt concrete and statistical analysis of the results.

\subsection{Sourcing and tests of materials}

The palm kernel shells (Elaeis guineensis fo. tenera) were obtained from directorate of University Farms (DUFARMS) in the Federal University of Agriculture, Abeokuta Nigeria. The coarse aggregate, fine aggregate and fillers were obtained from a local distributor while the bitumen was obtained from the Public works Corporation in Lagos state, Nigeria.

The preliminary laboratory tests and preparation of all asphalt cores were carried out according to ASTM specifications in the laboratory of the Civil Engineering department, Federal University of Agriculture, Abeokuta Nigeria, while other tests such as the Marshall Stability and flow test were carried out in Kopek construction company, Ibadan, Oyo State.

\subsection{Production of the nanomaterial}

The palm kernel shells to be used as fillers was burned in open air, ground to fine particles and calcined at $800^{\circ} \mathrm{C}$ for two hours in other to attain a pozollanic property before being nanostructured by the ball milling process. The ball milling was carried out at FIIRO, Lagos state with Ball milling machine Model 87002 Limoges_France, A50...43 for about 24hours. To further understand the properties of the obtained nanomaterial, the sample was characterized by X-Ray Fluorescence tests at Rolab research and diagnostic laboratory, Ibadan, Nigeria. The results are presented in Table 1.

\subsection{Determination of optimum bitumen content}

A suitable blend of aggregate was obtained as $40 \%$ Coarse aggregate, $45 \%$ fine aggregate and $15 \%$ filler material and tested for the determination of optimum bitumen content (OBC) with bitumen trial percentages of $4.5,5,5.56,6.5$ percentages. The average values of bitumen content at the maximum stability, maximum density and $4 \%$ air voids according to standards was selected as the optimum bitumen content. The results of the trial mixes with $4.5,5,5.56,6.5$ percentages of bitumen which were compacted and tested as presented in Table 2 with the OBC obtained as $6.1 \%$. 
Table 1: Oxide Composition of Calcined Nano-structured CN-PKS

\begin{tabular}{cc}
\hline COMPOUND & CN-PKS \\
\hline $\mathrm{SiO}_{2}$ & 50.2 \\
$\mathrm{Al}_{2} \mathrm{O}_{3}$ & 27.6 \\
$\mathrm{Fe}_{2} \mathrm{O}_{3}$ & 7.59 \\
$\mathrm{MnO}$ & 0.01 \\
$\mathrm{CaO}$ & 7.35 \\
$\mathrm{P}_{2} \mathrm{O}_{5}$ & 1.09 \\
$\mathrm{~K}_{2} \mathrm{O}$ & 1.88 \\
$\mathrm{TiO}_{2}$ & 2.42 \\
$\mathrm{MgO}$ & 0.45 \\
$\mathrm{Na}{ }_{2} \mathrm{O}$ & 0.12 \\
$\mathrm{Ba}$ & 441 \\
$\mathrm{Ce}$ & 62 \\
$\mathrm{Rb}$ & 88 \\
$\mathrm{Zr}$ & 73 \\
$\mathrm{Cr}$ & 97 \\
$\mathrm{Cu}$ & 33 \\
$\mathrm{Ni}$ & 42 \\
$\mathrm{~Pb}$ & 18 \\
\hline
\end{tabular}

Table 2: Volumetric properties to determine the Optimum Bitumen Content (OBC)

\begin{tabular}{|c|c|c|c|c|c|c|}
\hline \multirow{2}{*}{ Parameters } & \multirow{2}{*}{$\begin{array}{c}\text { Asphalt } \\
\text { Institute } \\
\text { specification } \\
\text { for medium } \\
\text { traffic roads }\end{array}$} & \multicolumn{5}{|c|}{ Bitumen Content (\%) } \\
\hline & & 4.5 & 5.0 & 5.5 & 6.0 & 6.5 \\
\hline $\begin{array}{l}\text { Marshall } \\
\text { Stability } \\
(\mathrm{KN})\end{array}$ & $\geq 7.5$ & 14.02 & 13.84 & 14.71 & 17.35 & 17.24 \\
\hline Flow (mm) & $2-4$ & 2.30 & 2.50 & 3.00 & 2.90 & 2.40 \\
\hline $\mathrm{Va}(\%)$ & $3-5$ & 1.82 & 1.93 & 1.01 & 2.26 & 2.09 \\
\hline $\operatorname{VFA}(\%)$ & $65-78$ & 82.88 & 81.02 & 89.55 & 78.19 & 78.87 \\
\hline $\begin{array}{l}\text { VMA (\%) } \\
\text { Bulk }\end{array}$ & & 10.67 & 10.20 & 9.68 & 10.38 & 10.85 \\
\hline $\begin{array}{l}\text { Density } \\
\left(\mathrm{g} / \mathrm{cm}^{3}\right)\end{array}$ & & 2.31 & 2.33 & 2.36 & 2.35 & 2.35 \\
\hline
\end{tabular}

*Note: $\mathrm{Va}=$ Air voids

VFA $=$ Voids filled with Asphalt

$\mathrm{VMA}=$ Voids in mineral aggregate

\subsection{Evaluation of the effect of palm kernel shell and its nanomaterial on the volumetric and Marshall Properties of asphalt concrete}

The palm kernel shell and its calcined nanomaterial (PKS \& CN-PKS) were then used to replace the coarse aggregates and the filler material at $5,10,15,20$ and $25 \%$ each in the same asphalt mix.
The materials were mixed together and compacted according to Marshall Procedures with 50 blows on both sides to obtain cylindrical samples for the Marshall Stability tests. Volumetric parameters such as density, void in total mix, voids filled with bitumen as well as marshal stability and flow were carried out on asphalt cores to evaluate the strength of the mixes. The results are presented in Table 4 .

\subsection{Data Analysis}

The results obtained in this study were imputed in Microsoft excel (2013 version) and were later transported to SPSS (BMI incorporated) version 20 for further analysis. Differences in mean values were compared using one-way Analysis of Variance (ANOVA), and were further separated using Duncan Multiple Range Test (DMRT) as a single post-Hoc Test. Linear Regression model were also computed to measure relationships between two variables and also for predictions. P-values of less than 0.05 (i.e 95\% confidence level) were considered to be significant $(\mathrm{p}<0.05)$.

\section{Results and Discussion}

\subsection{Oxide Composition of Calcined Nano-structured $P K S(C N-P K S)$}

The oxide composition of calcined nanostructured palm kernel shell (CN-PKS) obtained from $\mathrm{XRF}$ procedure is given in Table 1. Calcium oxide $(\mathrm{CaO})$ content is $7.35 \%$ and silicon dioxide $\left(\mathrm{SiO}_{2}\right)$ content is $50.2 \%$. The $\mathrm{CaO} / \mathrm{SiO}_{2}$ ratio, which indicates its cementing potential, is 0.15 . Also, $\mathrm{SiO}_{2}$ $+\mathrm{Al}_{2} \mathrm{O}_{3}+\mathrm{Fe}_{2} \mathrm{O}_{3}=85.41$. It can be deduced from the $\mathrm{XRF}$ results that, the CN-PKS is a pozzolan since it contained a great percentage of $\mathrm{SiO}_{2}, \mathrm{Al}_{2} \mathrm{O}_{3}$, and $\mathrm{Fe}_{2} \mathrm{O}_{3}[12]$.

\subsection{The preliminary tests of aggregates}

The results of the preliminary tests of aggregates are shown in the Table 3 below. The properties of all materials met specified standards of materials to be used in asphalt concrete [13]. The aggregate gradation curves for the fine and coarse aggregates are shown in figures 1 and 2. Figure 3 shows the upper and lower limits with the total mix gradation of aggregates used in this research. According to IS specification, the PKS can be classified as an exceptionally strong material that can resist sudden impact or shock to an extent due to the 
low AIV values and can resist crusing under gradual compressive loading due to the low ACV valued. These properties are necessary for roads or pavements to be able to resist shock and withstand crushing under traffic loading.
3.4 Relationship between percentage replacement of $P K S \& C N-P K S$ and volumetric properties of asphalt concrete using linear regression model

As displayed in figure 4, no significant relationship existed between percentage PKS replacement and stability, VFA and VMA. The voids in an asphalt mixture are directly related to density; thus, density must be closely controlled to insure that the voids stay within an acceptable range (Brown, 1990).

Table 3: The preliminary tests of aggregates

\begin{tabular}{|c|c|c|c|c|c|c|}
\hline Property & Specifications & $\begin{array}{l}\text { Coarse } \\
\text { Aggregate }\end{array}$ & $\begin{array}{l}\text { Fine } \\
\text { Aggregates }\end{array}$ & Filler & PKS & Bitumen \\
\hline Specific Gravity & ASTM D 854 & 2.67 & 2.65 & 2.63 & 1.16 & 1.01 \\
\hline $\operatorname{AIV}(\%)$ & \multirow{2}{*}{ IS: 2386(Part IV) 1963} & 22.01 & - & - & 5.75 & - \\
\hline $\operatorname{ACV}(\%)$ & & 20.01 & - & - & 8.07 & - \\
\hline Penetration $(\%)$ & AASHTO T-49 & - & - & - & - & 62.3 \\
\hline Flash Point $\left({ }^{\circ} \mathrm{C}\right)$ & \multirow{2}{*}{ IS : 1209-1978 } & - & - & - & - & 283 \\
\hline Fire Point $\left({ }^{\circ} \mathrm{C}\right)$ & & - & - & - & - & 303 \\
\hline
\end{tabular}

Note: AIV = Aggregate Impact Value, ACV = Aggregate Crushing Value

\subsection{Marshall Stability, flow and air voids of partially} replaced coarse and filler aggregate with PKS \% $C N-P K S$ respectively in asphalt concrete

The suitability of mix for paving is decided on the basis of Marshall Stability and flow value, but some other parameters like unit weight of mix, percent air voids and voids in mineral aggregates are important to be taken into consideration for the durability of the flexible pavement. Table 4 shows the results of, Marshall and volumetric properties at mix proportions of PKS \& CN-PKS replacement in the same mix.

With respect to Marshall Stability and flow values, all the percent of CN-PKS mix proportions are within the limits of specification including the control mix. The optimum stability and percentage air void value was recorded at $20 \%$. This is an implication that partial replacement with PKS \& CNPKS as coarse and filler respectively at $20 \%$ in hot mixed asphalt can improve the strength of medium trafficked roads. However, at $5 \%$, and $15 \%$ of the replacement, the percent air void is very low about $2.42 \%$ and $1.87 \%$ (Table 4 ) respectively. Utilizing this replacement at this proportion will most likely cause rutting and bleeding of the flexible pavement because there will not be enough air voids for the bitumen to occupy during traffic loading [14].

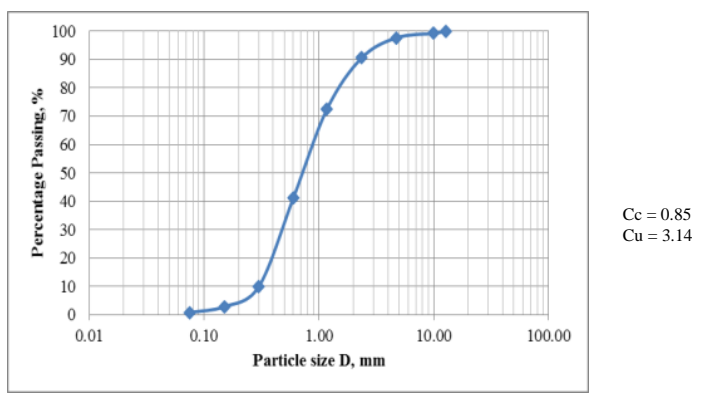

Figure 1: Particle Size Distribution for Fine Aggregate

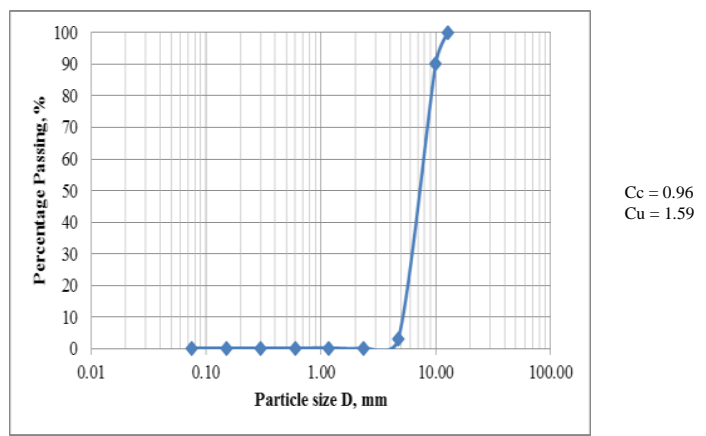

Figure 2: Particle Size Distribution for Coarse Aggregate

Interestingly, a very strong inverse relationship existed between the percentage CN-PKS replacement and Bulk Density $(\mathrm{p}<0.05)$, with $\mathrm{R}^{2}$ of 0.981 , an indication that $98.1 \%$ of the variations observed in bulk density were being accounted for by percentage 
of CN-PKS in the Mix. i.e. bulk density reduced with increase in percentage CN-PKS. The equation that predicts this is given as Bulk density $=-0.0091(\%$ CN-PKS) +2.3649 as shown in Figure 4f. Also, air voids and flow values were significantly affected by percentage CN-PKS replacement. While $56.6 \%$ of the variations observed in Va values were accounted for by percent CN-PKS replacement, about $87.7 \%$ of the variations in flow values were being accounted for by percent CN-PKS replacement (Figure 4b). The low air voids recorded at $5 \%$, and $15 \%$ coarse and filler replacement (with values 2.42 and 1.87 respectively) shows that utilizing PKS \& CN-PKS at this proportion will most likely cause rutting and bleeding of the flexible pavement because there will not be enough air voids for the bitumen to occupy during traffic loading (Olutaiwo and Owolabi, 2015).

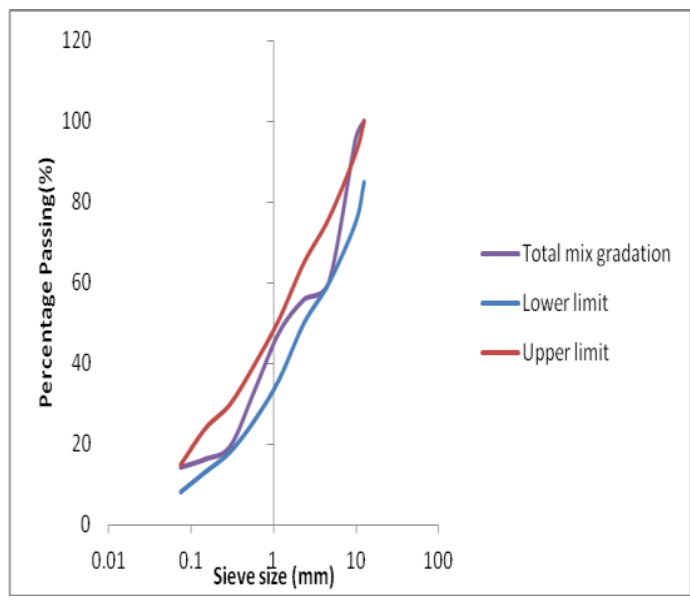

Figure 3: Upper and lower limits with Total mix gradation of aggregates used in this study

Table 4: Volumetric properties of partially replaced coarse and filler aggregate with PKS and CN-PKS in asphalt concrete with specifications according to asphalt institute (AI).

\begin{tabular}{|c|c|c|c|c|c|c|c|}
\hline \multirow{2}{*}{ Parameters } & \multirow{2}{*}{$\begin{array}{c}\text { Asphalt Institute } \\
\text { specification for } \\
\text { medium traffic } \\
\text { roads } \\
\end{array}$} & \multicolumn{6}{|c|}{ PKS and CN-PKS REPLACEMENT (\%) } \\
\hline & & $\mathbf{0}$ & 5 & 10 & 15 & 20 & 25 \\
\hline Marshall Stability (KN) & $\geq 7.5$ & 14.41 & 12.95 & 13.45 & 11.18 & 15.26 & 12.39 \\
\hline Flow (mm) & $2-4$ & 2.50 & 3.50 & 3.90 & 3.00 & 3.00 & 3.01 \\
\hline $\mathrm{Va}(\%)$ & $3-5$ & 3.61 & 2.42 & 2.73 & 1.87 & 3.62 & 3.20 \\
\hline VFA $(\%)$ & $65-78$ & 71.55 & 81.29 & 77.89 & 85.87 & 69.35 & 74.42 \\
\hline $\operatorname{VMA}(\%)$ & & 12.70 & 12.93 & 12.36 & 13.22 & 11.81 & 12.50 \\
\hline Bulk Density $\left(\mathrm{gm} / \mathrm{cm}^{3}\right)$ & & 2.37 & 2.31 & 2.28 & 2.21 & 2.20 & 2.14 \\
\hline
\end{tabular}
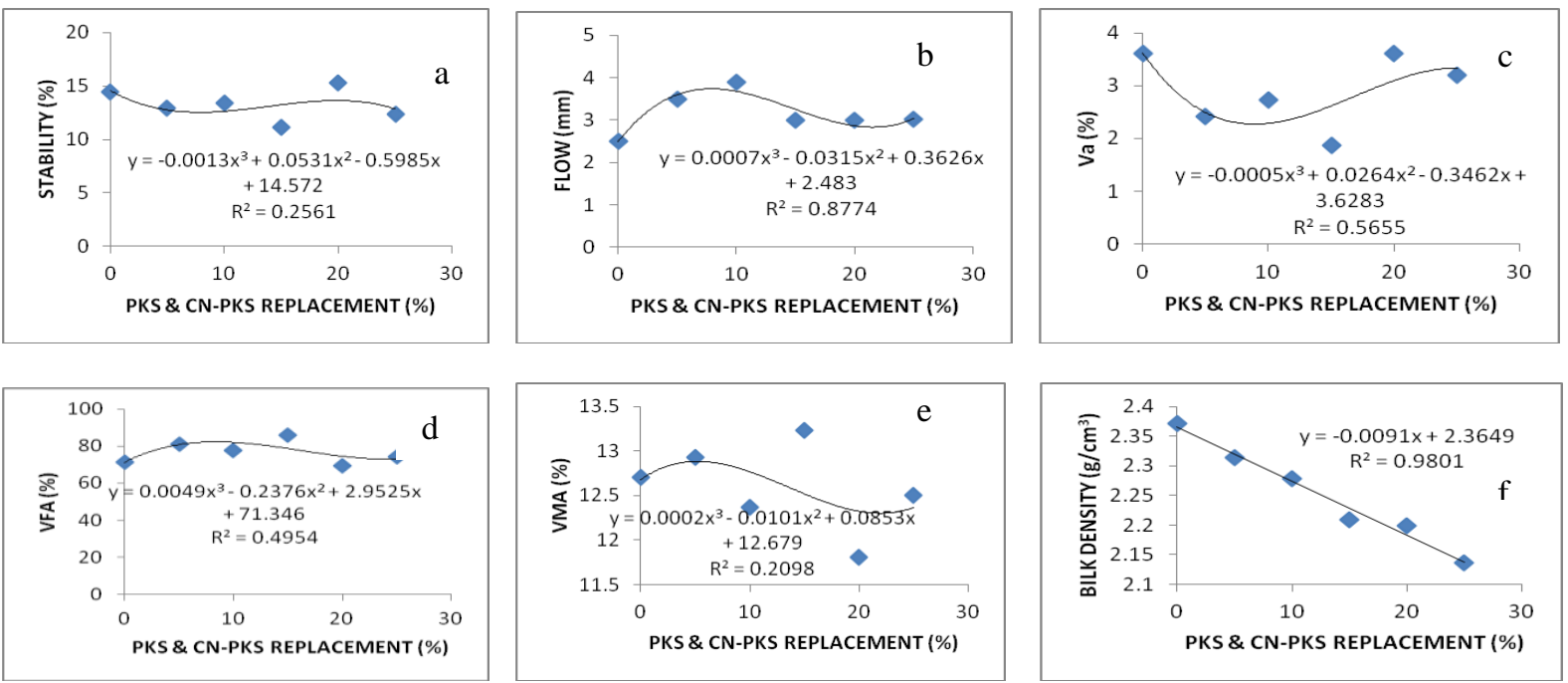

Figure 4: Relationship between percentage PKS \& CN-PKS replacement and (a) Stability, (b) flow, (c-f) Volumetric properties of asphalt concrete 


\section{Conclusion}

According to the results of the experimental investigations on the performance of the modified mixes for PKS \& CN-PKS, the following conclusions were derived: All the percent of PKS \& CN-PKS mix proportions are within the limits of specification. The optimum stability and percentage air void value was recorded at $20 \%$. This implied partial replacement with PKS and CN-PKS as coarse and filler at 20\% each, together in the same asphalt concrete mix can improve the properties of mixes for medium trafficked roads.

However, at 5\%, and $15 \%$ PKS and CN-PKS replacement, the percent air void is low. This means utilizing PKS and CN-PKS at this proportion will most likely cause rutting and bleeding of the flexible pavement because there will not be enough air voids for the bitumen to occupy during traffic loading.

\section{Acknowledgements}

We want to appreciate the effort of $\mathrm{Mr}$. Cosmos and Dr. Babalola for the assistance provided during compaction for the different mixes. We also want to appreciate the Public works Corporation in Lagos state, Nigeria for providing us with the bitumen used for this research.

\section{References}

[1] M. Losa, P. Leandri, P. and R. Bacci, "Mechanical and Performance-Related Properties of Asphalt Mixes Containing Expanded Clay Aggregate", Transportation Research Record, 2051: 23-30. http://dx.doi.org/10.3141/2051-04, 2008.

[2] H.L. Lehmann, and V. Adam, "Use of Expanded Clay Aggregate in Bituminous Construction", Highway Re-search Board Proceedings, 38:398-407, 1959.

[3]. V. Aams, and S.C. Shah, "Evaluation of Open-Graded PlanMix Real Surfaces for Correction of Slippery Pave-ments", Transportation Research Record, 523:88-96, 2008.

[4]. R.B. Mallick, F.P. Hooper, S. O'Brien, and M. Kashi, "Evaluation of Use of Synthetic Lightweight Aggregate in Hot-Mix Asphalt". Transportation Research Record, 1891: 17. http://dx.doi.org/10.3141/1891-01, 2004.

[5] F.M. Canestrari, G. Bocci, G. Ferroti, and P. Pasquini, "Mechanical Caracterization of Environmentally Friendly Mixtures" Proceeding of the International Conference on Advanced Characterization of Pavement and Soil Engineering Materials, Greece, June 2007, 1643-1652, 2007.

[6] P.N. Ndoke, "Performance of Palm Kernel Shells as a Partial replacement for Coarse Aggregate in Asphalt Concrete". Leonardo Electronic Journal of Practices and Technologies, 9: 145-152, 2006.

[7] R. Nagendran, "Agricultural waste and pollution", In Waste; Academic Press: Cambridge, MA, USA, pp. 341-355, 2011.
[8] E.O. Olukanni, O.J. Oyedepo, B.D. Oluyemi-Ayibiowu, D.A. Alo, and S.G. Falayi, "Laboratory Investigation of Using Agricultural and Solid Waste in Hot-Mix Asphalt for Road Pavement". Indian Journal of Engineering, 16:102-112, 2019

[9] D.Y. Osei, and E.N. Jackson, "Experimental Study on Palm Kernel Shells as Coarse Aggregates in Concrete", International Journal of Scientific and Engineering Research, 3(8): ISSN 2229-5518, 2005.

[10] M. Aslam, P. Shafigh, M.Z. Jumaat, and M. Lachemi, "Benefits of Using Blended Waste Coarse Lightweight Aggregates in Structural Lightweight Aggregate Concrete", Journal of Cleaner Production, 119: 108-117, 2016.

[11] M.C. Roco, R.S. Williams, and P. Alivisatos, "Nanotechnology Research Directions", IWGN Research Report, Committee on Technology, Interagency Working Group on Nanoscience, Engineering and Technology (IWGN), National Science and Technology Council, 1999.

[12] E.J. Ejelikwu, M. Joel, and I. Usoro, "Palm Kernel Shell Ash Stabilization of Reclaimed Asphalt Pavements, as Highway Pavement Materials". Journal of Sustainable Development and Environmental Protection, 2(1): 98 - 111, 2012.

[13] BS 1377, "Methods of Testing Soils for Civil Engineering Purposes." Technical Information Services Department, CNL Technical Information Services, BSI Publications, 389 Chiswick High Road London W4 4AL, 1990.

[14] A. Olutaiwo, and A. Owolabi, "Investigation of the Effects of Partial Replacement of Coarse Aggregate with Graded Palm Kernel Shell in Asphaltic Binder Course", British Journal of Applied Science \& Technology, 10(3): 1-13, 2015. 